\title{
A Study Protocol to Assess Accessibility, Utilization, and Compliance on Adolescent Sexual Reproductive Health Services in South Sudan Context
}

\author{
Article by Katwesige wycliff \\ Masters of Public Health, Texila American University, Uganda \\ E-mail: katnagaish@yahoo.com
}

\begin{abstract}
Introduction: Provision of Sexual reproductive health (SRH) to people living in complex humanitarian emergencies is quite challenging. According to World Health Organization (WHO), addressing the health needs of adolescents living in crisis and fragile settings is a fundamental step on the pathway to both sustain the gains of the millennium development goals and achieve the new 2030 sustainable development goals. South Sudan's humanitarian situation remains fragile, precarious, complex and uncertain. The capacity of the nation to respond to the health of its people is crumbled. More than 4.9 million People are in dire need of humanitarian assistance, maternal mortality rate is $789,33 \%$ of the population is youth under 24years. There remain uncertainties as to whether the humanitarian response efforts are taking account of adolescent needs. This project will assess the accessibility, utilization and compliance of adolescents (aged 10-19 years) to health services provision within WHO set standards from selected camps in South Sudan. The study results shall inform advocacy and programming of SRH services by humanitarian partners.

Methodology: The search criteria will include; Cochrane libraries, PubMed, and others. Literature will be organized and referenced by research software like Mendeley. A cross-sectional study using qualitative and quantitative approaches will be conducted. Results will be analyzed using WHO recommended expand-net framework.

Ethics: Participation in an assessment will be voluntary. Parental consent for minors will be obtained before participating in the study. Approval from South Sudan Ministry of Health ethical committee shall be sought.1951 conventions of rights of refugees will be respected.

Foot note: The cross-section, Complex. Humanitarian, Adolescent, sexual Reproductive Health, Refugees, South Sudan

\section{Rationale and background information}

According to World Health Organization (WHO), Sexual health refers to as a state of physical, mental emotional and social well-being as related to sexuality, and not merely the absence of disease, or infirmity" (WHO 2000). Although the Global strategy for women and adolescents calls for "integrated solutions" based on dignity, respect, quality, integrated Healthcare ${ }^{1}$.The response in South Sudan seem more fragmented with different agencies providing what they feel they can best offer. As Sexual health requires a more careful approach to both sexuality and sexual relationships, as well as the possibility of experiencing pleasurable and safe sex, without coercion, discrimination, and violence, This study identifies four categories of Adolescent Sexual reproductive Health (ASRH) services intervention that exist, Thus (1) facility-based, (2) out-of-facility based, (3)programs that reach marginalized or vulnerable populations, (4) interventions to generate demand and/or community acceptance ${ }^{2}$. In September 2015 was globally marked as a year of defining moments for children and adolescents as well as the end point for United Nations Millennium Development Goals (MDG) and the adoption of recent Sustainable Development Goals (SDG) meant to transform the world in next 15 years ${ }^{3}$. It also included the $20^{\text {th }}$ anniversary to celebrate action plans developed at the International Conference on Population and Development (ICPD) which defined SRH services and explicitly declared SRH as a fundamental human right, including for adolescent ${ }^{2}$. The current strategy is based on lessons learned and recent evidence and
\end{abstract}


Texila International Journal of Public Health

Volume 4, Issue 4, Dec 2016

is focused on critical groups within a given population such as women, adolescents and children living in fragile and conflict settings. In 1994 UN conference, the "Women's Commission for Refugee Women and Children" also reported major gaps in the provision of SRH services to refugees and others affected by crises(United Nations \& Conference, 2014). As Adolescence is typically characterized by a desire for information, and experimentation, the need to support adolescents in Complex setting like South Sudan is indeed dire ${ }^{5}$. Since adolescents contribute to one-fifth of the world's population(WHO, 2009), and also associated with high risk of pregnancy-related mortality compared to older women, such risks are indeed higher for adolescents in crisis settings ${ }^{7}$.Since $85 \%$ of adolescents are said to live in low-resource settings, current evidence approves that adolescent SRH is currently an area in need of research ${ }^{8}$. The $21^{\text {st }}$ century has faced challenges such as conflicts and wars especially in the developing world, which has led to a considerable number of people have either been internally displaced (IDPs) or found themselves seeking asylum (Refugees). Thus, adolescents have found themselves at the center of complex/conflict situations. Recently, the environment in south Sudan is now referred to as a "complex emergency" by Aid workers ${ }^{9}$. Before the December 2013 conflict, it was referred to as a "period of transition and recovery". The term complex has been adopted in this project to reflect on the complexity of the situation in which South Sudanese adolescents live as characterized by volatile States and others of relative stability.

According to WHO global report on world's adolescents, a standard driven approach for improving the quality of health care services among adolescents is highly recommended. The world's health body has therefore set global operational standards for quality health care for adolescents in order for them to find it easier to obtain the health care services they need (WHO 2015). Recently, at a September 2015 UN general assembly, an ambitious 15 year plan to pave a road map for improving lives of people throughout the world was adopted. This plan referred to as Sustainable Development Goals (SDG) consists of 17 goals and 189 targets calling for urgent attention to enhancing the availability and accessibility of sexual and reproductive health interventions required for the dignity and health of adolescents and children in those in emergency settings" 10 .

Of recent, the South Sudan political situation remains fragile following over 2years of hostilities including the most recent fallout between government and Rebel forces. Efforts to address long-term resilience and support national capacity for the delivery of basic health services were shelved. The grim, fragile, precarious, complex and uncertain humanitarian outlook is indeed troubling to the provision of adolescent health services. A humanitarian crisis is herein referred to as an "exceptional and a generalized threat to human life, health or subsistence". Although the perspectives for humanitarian disasters for children and adolescents from global view to save lives can be easily understood, the previous approach by the global community including WHO, World Bank, with other specific initiatives dedicated to adolescent health failed to address these complex issues ${ }^{11}$.

Meanwhile, as more South Sudanese seek refuge in neighboring countries like Uganda, an influx of refugees, above 350,000 was projected to arrive in South Sudan by the year 2013 (UN OCHA 2012). According to Amnesty International on July 6, 2014,over 10,000 deaths and 2 million people were displaced following the conflict ${ }^{12}$. By 2014 South Sudan was hosting over 250,000 refugees from Ethiopia, Central African Republic (CAR), Democratic republic of Congo (DRC) and Sudan. At the same time more than 1.4 million, South Sudanese were displaced internally following these hostilities and worsened by June 2016 clashes. Basing on this context, United Nations High Commissioner for Refugees (UNHCR) strategic mission for South Sudan in 2015 was to improve refugee status in settlements by enhancing the provision of health, and other services (UNHCR, 2015). Recently, the Common Humanitarian Fund (CHF) took responsibility in leading humanitarian efforts while enhancing its coordination in order to mobilize resources for the broader response and boost the visibility of the CHF both in the country and internationally ${ }^{13}$.More research is needed to determine the best linguistically and culturally acceptable means to deliver sexually and reproductive health services to vulnerable and marginalized populations. This study will answer questions aboutwhether SRH needs of adolescents living in such complex setting are accessible, utilized and meet the WHO set standards. 


\section{Problem statement and justification}

Frequent violence and conflicts in Africa are shown to have negative impacts on its society for instance current situation in South Sudan, previous conflicts in the Democratic republic of Congo, Uganda, and Rwanda which has experienced brutal civil wars in last 30years. Based on this context, following the 2013 Juba hostilities, refugees living in South Sudan continue to face serious and life-threatening protection issues, humanitarian workers were also killed on the mission (UNOCHA 2015). This situation, coupled with the total erosion of law and order in the refugee and IDP camps, manyyouths especially adolescents remain vulnerable to the complex environments impacting negatively on their health. The UNHCR mission in South Sudan is mandated to ensure refugees are protected and helped in such context $^{14}$

According to report by United Nations Population Fund (UNFPA) on South Sudan, nearly 4.9 million people are in dire need of humanitarian assistance, I.5 million are internally Displaced and live in IDP camps, Around 2.8 million people were targeted for reproductive health services, the contraceptive prevalence rate stands at 3, proportion of its youth aged 10-24years accounts to nearly 33\% with Maternal mortality ratio of 789 (OCHA 2014). According to UNOCHA 2016, the population in need is estimated at 6.1 million out of which 4.7 million are in need of Health services and 2.7 million are only targeted by the

humanitarian response ${ }^{16}$.WHO is currently concerned with increasing sexual violence and limited coverage of skilled delivery care in many areas increasing the risks of maternal morbidity and mortality. More research to establish efficient means of delivering services to reach marginalized or vulnerable adolescents like refugees is still demanding ${ }^{2}$.

Recent study from Ajoung Thok a refugee camp in South Sudan revealed quite a large number of unmet adolescent SRH needs in terms of coordination, assessment and monitoring including major gaps on facility based ASRH services, community-based ASRH Services and communication (Africa Humanitarian Agency AHA, 2015). The study further emphasized strong rooted cultural beliefs that affect the delivery of ASRH services in the camp. Unwanted teenage pregnancies were spelled out as a major issue among adolescent girls in this settlement. But this study did not account for the views of teenage mothers partly due to the social and cultural context of people living in the camp. The findings were limited to one settlement hence situation may not be similar to other camps and their generalization is difficult. Furthermore, the study analysis did not fully conform to WHO recommended standard frameworks. In addition, related studies were conducted by the Inter-Agency Working Group (IAWG) for three countries (including south Sudan) to assess Reproductive Health services in Humanitarian settings, also revealed gaps ranging from limited knowledge and skills among service providers to cultural barriers in accessing Reproductive Health (RH) services among beneficiaries. This study also faced limitations ranging from security barriers to a lack of conformity with data analysis protocols recommended by WHO frameworks and limitations on its impact of driving policy change in South Sudan as well. Likewise, After long periods of planning to address ASRH, it's now evident that strengthening access and quality of health services does not alone improve health outcomes ${ }^{17}$. Hence, the call for Cutting-edge research on a measure of equity, accountability, and key determinants of SRH as well as informing UN agencies, with specific analyses and technical inputs has gained shape ${ }^{18}$.

In an attempt to generate demand for scaling up and increasing utilization of health services in context to basic primary health care for adolescents, as well as ensuring public health responsibility to help them protect their health and building on the Ajuong Thok research findings with its recommendations, this study will further assess whether adolescent health services entire South Sudan camp context meet set standards and are well accessed and utilized. The need for humanitarian agencies in the country to focus material and financial support to women, children, and adolescents in such conflict setting are highly demanding ${ }^{11}$. This study is justified by dire need of scaling up and improving the quality of assistance provided to vulnerable persons living humanitarian crisis and other complex settings and will synthesize practically sound evidence base to inform and update advocacy, policy change, and programming of ASRH services ${ }^{8}$ 
Texila International Journal of Public Health

Volume 4, Issue 4, Dec 2016

\section{Study goals and objectives}

\section{Goal}

To assess the factors affecting access, utilization as well as compliance with adolescent sexual reproductive health (ASRH) services provision in accordance to WHO set standards in selected complex humanitarian settings within South Sudan

\section{Research objective}

1. To establish the factors that affect access to ASRH services in a selected complex humanitarian setting within South Sudan

2. To examine the level of utilization of ASRH services in such setting within South Sudan

3. To assess compliance levels in the provision ASRH services in a similar setting within South Sudan to the current WHO set standards.

\section{Research questions}

1. What are the factors that affect access to ASRH services in selected complex humanitarian settings within South Sudan?

2. What could be utilization level of such ASRH services the same setting within South Sudan?

3. Are these ASRH services in a selected setting within South Sudan compliant with WHO set standards?

\section{Hypothesis}

Research on adolescent sexual reproductive health in complex/conflict humanitarian is currently limited ${ }^{2}$. This study will be based on the hypothesis that Identification of special beliefs which predict sexual risk and protective behaviors could lead to the design of linguistically specific interventions. Adolescents living in South Sudan environment are most likely to experience factors that limit their access to, low utilization of ASRHS and provisions of such services are likely to be below WHO set standards. 


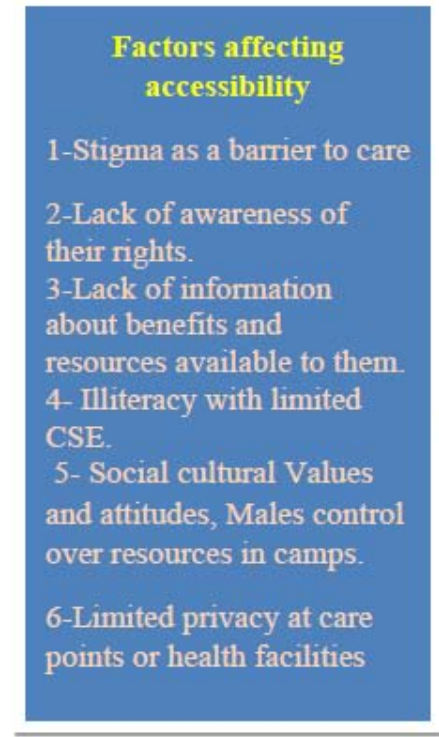

\section{WHO set standards \\ Standard 1.Adolescent Health} Literacy.

Standard 2.Community Support

Standard 3.Appropriate package of services

Standard 4.Providers competencies

Standard 5.Facility characteristics

Standard 6.Equity and non-

discrimination

Standard 7.Data and quality

improvement

Standard 8.Adolescents' participation.
The level of utilization in refugee and IDP camps.

1-Limimited use of package for adolescent care services (counseling treatment, Comprehensive sexual education, and others)

2-Limited Knowledge on adolescent health services in their setting

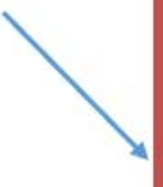

Adolescent Sexual Reproductive (SRH) services

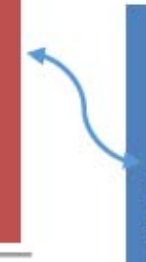

Loss of the time for

learning and opportunity to build a good future.

2-Loss of place or home or

places of belonging.

3- Loss of family, friends

and significant adult role

Models.

4-Loss of order, routines

and meaningful activities,

and the onset of a time of

waste and, emptiness;

5-Loss of health or capacity

through injury, illness and

poor; and

6-Loss of trust in response

to personal or witnessed

experiences of harm or

abuse and sexual

exploitation

Fig 1. Conceptual framework

\section{The Research methodology}

\section{Settings for this study}

\section{Area of Study}

The study will be conducted amongst refugees and internally displaced persons living in camps in South Sudan. This will involve, South Sudanese in IDPs, and the refugees living in Settlement camps. The refugees have origins from Sudan, Democratic Republic of Congo (DRC) and Ethiopia. The refugee's population in South Sudan is 300,000 and IDPs 1.3million(UNOCHA 2016). The camps to be surveyed will undergo a random selection from among the 12 refugee settlement camps within South Sudan and at least 3 UN managed Internally Displaced Person camps (IDPs). 
Texila International Journal of Public Health

Volume 4, Issue 4, Dec 2016

\section{Our study population}

The participants in this study will be composed of both in and out of school adolescents aged (10-19 years). Our focus of the investigation will include; adolescents themselves, the Ministry of Health(MOH) staffs, None Governmental Organizations staff in Country response clusters, parents of these adolescents and their guardians, their teachers and religious as well as cultural leaders among others. Inclusive will be both genders supporting or living in either refugee camps. The study will adhere to rights of vulnerable populations in line with 1951 Universal Declaration of Human Rights and especially Articles 6 and 14, in particular, concerning the rights of refugees ${ }^{19}$.

\section{Study design}

We shall investigate the factors that affect access, utilization levels and compliance to ASRH services in the selected IDP and refugees camps. This will be entirely a cross-sectional study applying both quantitative and qualitative methods approaches to allow triangulation. The quantitative methodology will include face to face interviews and assessment of the existing Health information system (HIS) data. On the other hand, thequalitative methodology will involve Focused group discussions (FGD) as well as Key Informants (KIs). The study will be conducted in early 2017, upon receiving funds for this project.

\section{Population to be studied}

The study will involve both adolescents, teachers as well as health staff from refugee's schools and health units the Camps. Consent shall be sought for minors who will participate in this study from their parents and guardians. Study participation by all respondents shall be maintained on voluntary basis and in line with conventions relating to status of refugees ${ }^{20}$

\section{Inclusion and exclusion criteria}

\section{Inclusion}

All adolescents aged 10-19 years and any technical staff like teachers or health workers within the refugee and IDP camps.

\section{Exclusion}

All technical staff like teachers within the refugees or IDP camps who refuse to participate or decide to withdraw from the study and those adolescents who decline to participate in interviews will be excluded.

\section{Search criteria}

Inclusion criterion; We intend to search publications and written articles on adolescent living in crisis and other humanitarian setting and those on reproductive health services in refugee and IDP camps, the effect of wars and conflicts, WHO Library, World Bank report, with publication ranges between 2005 and 2015.

Exclusion criterion: All the non-English publications or publications before 2005 will not be included in our search.

\section{Sample size determination}

We shall use census for a small population less than 200 for example as a technique to establish the sample size and the number of technical staff will be interviewed to eliminate errors of sampling and provision of data to all the individuals in the study group. Sample size will be the entire adolescent's population (Glenn, 1992). To predict non-response or badly filled, damaged questionnaires we shall add $10 \%$. 


\section{Sample selection procedure}

We shall conduct a multi-stage, KI purposeful and random sampling. The community respondents will be sampled as follows: A list of all the names of individuals in the 12 camps of Refugees and 3 IDP camps will be populated. Every camp name will be written on a separate piece of paper, folded to ensure that all camps have the same chance of being selected as well. The PI shall then randomly pick 4 papers with no replacements. This will generate a total of four camps to be included in the study with each camp having an equal opportunity of being selected. Hence, the 4 Camps will be a representative for South Sudan Refugees and IDP Settlements.

\section{Data collection}

\section{Primary data collection}

\section{Quantitative data collection}

Semi- structured questionnaire will be administered by PI and trained research assistants (RAs) to the heads of households and adolescents.

\section{Qualitative data collection}

Key informants (KI) selected purposively will be interviewed using a question guide. They will include the following: Ministry of Health, Ministry of Education, Directors, Refugee Commissions, UNHCR staffs, NGOs partners at the camps, WHO staff and UNFPA staff.

\section{Secondary data}

This will involve a summary of existing data, previous research reports, books, journals, government and partner NGO statistics and online databases.

\section{Recruitment of study subjects}

The study team will work in close consultation with community leadership (formal and informal) to plan, identify and recruit potential participants for each site. The strategies to recruit members will thereafter be determined by the type and number of data collection activities above. These will be very flexible and modifiable. In case newer topics, research questions, or subpopulations emerge related to the study or initial strategies do not result in the desired number of recruits, or if certain data collection activities of populations do not prove useful in answering the research questions, the criteria for selection will change. The research team shall respect and be responsive to the guidance and advice of local expertise and local leadership (camp and Payam leaderships).

\section{Training interviewers}

The fist training will consist of 2 days classroom based exercises. Didactic teaching kept to a minimum and shall be focused on description methodology its rationale. We shall spend more time on trainees to practice the methods on each other as well providing feedback to the group. Addition observation and systematic data collection methods training will be provided in the field sites just prior to their use.

\section{The management of data and statistical analysis}

\section{Study selection}

For secondary data analysis, three authors (Principal Investigator and 2 research consultants) will independently examine titles and abstracts of selected studies to eliminate none relevant studies. For those studies that meet our inclusion criteria, full texts will be retrieved and two reviewers will assess their final eligibility against the inclusion criteria. As studies in this field for the case of South Sudan and other humanitarian settings, 4 studies will be included in this study. 
Texila International Journal of Public Health

Volume 4, Issue 4, Dec 2016

\section{Management of data}

We shall install, special research software such as Mendeley or Zotero on laptops during collection of secondary data. Articles that will be found eligible for our study will be downloaded and inputted accordingly, author will then independently extract the following details;

1) Title, authors, status of publication, journals, founders and date of publications.

2) Categorization of crisis whether disaster or conflict and the type of crisis whether armed conflict, droughts, landslides, tsunami, and cyclone, hurricanes floods, earthquakes, volcanoes and others

3) How was the nature of onset slow or rapid, stage reported, active or recovery setting and location urban or rural?

We shall dispense semi-structured questionnaires, digital audio tape recordings, emails during primary data collections to field partners and shall observe events as well. Collected data will be discussed and summarized in line with key study areas limited to 3-5 issues as explained during the training workshop. We shall integrate the findings from this background to correlate findings from the field and provide a broader context. Reports will be sent to principal investigator who will provide feedback. The specific choice of people to be interviewed will depend on the camp location. The interviewees might include, policy-makers and program managers, service providers in humanitarian settings, camp managers and health workers including CHWs, as well.

Pre-test of the instruments used will be conducted familiarize team members with the different instruments through an interactive process of developing them included in role-plays and re-testing them before the fieldwork begins. This will enrich team experience with qualitative interview techniques during the training sessions.

Dr. Wamala Joseph is a co-investigator in this study. He works with WHO epidemiology department in South Sudan, he contributed to the design of this study and will lend support to work out the sample size and data analysis sections of the study. He will create a study database, perform data validity checking's concurrent data analysis as well. The standard frameworks and tools like WHO expand net frameworks will be deployed in during analysis.

Variations in the findings from various camp settings due to other factors are expected. If further studies for review are identified, further investigations shall be conducted based on its heterogeneity within groupings here below;

- Place of care such as facility-based versus non-facility or community services)

- The status of displacement for example IDPs versus refugees and the surrounding host communities)

- The type of providers likes skilled versus unskilled providers.

- The current type of service delivery like stationary versus mobile clinics

\section{Expected study outcomes}

\section{Expected primary outcomes}

- The evidence of access and level of coverage of ASRH services in the camps such as the coverage of school health programs, school dropout rates by gender, STIs prevalences among adolescents. Barriers to service access like health worker attitudes.

- The current utilization of overall health services by youth like antenatal (ANC) and family Planning (FP) attendances by adolescents as well as Sexual gender-based violence (SGBV) in the camps.

- Update knowledge in the existing level of standards in services provided to adolescents.

\section{Secondary outcomes}

- Improvement in the quality services provided to adolescents in the camps evidenced by humanitarian agencies adhering to WHO recommended practices guidelines and approaches.

- Improvements in quality of statistics for informing adolescent health programming in Humanitarian emergency settings in Sub-Saharan Africa. 
- Enhanced refugees and IDP protection services reduction in SGBV prevalence rates in the camps as a result of ASRH services scaled up.

\section{Dissemination of results and publication policy}

The principal investigator (PI) will take lead in the publication of the research findings. All pertinent contributors to this research project will be included in the publication as well as major funders.

\section{Ethics and dissemination}

Those selected to participate in this study will do so on entirely voluntary basis and such participants will be allowed to respond freely to the questions. Interviews will be conducted outside school operating hours and in the absentia of their parents and teachers from the room of interview. Questions will not include confidential information to interviewees. There will likely be no ethical committee to review and authorize this study relative to the current security situation and capacity toground. However, prior to the commencement of this study, an interagency committee including members from UNCHR, ACROSS, WHO, and other relevant partners will be established to advise on the study justification and methodology that will respect refugee and other vulnerable population rights. The findings from this study will be published as per the decision of funders.

\section{Project duration}

The study will last a period of 8 to 10 months depending on circumstances in the field including security and access issues on the ground.

\section{Project timelines and limitations}

Due to the current security situation in South Sudan, there is the likelihood of study being affected by security risks in the field. Communication infrastructure is very limited hence road transport in some areas like the Yei, Bor will not be feasible. Hence additional expenses in booking flights for investigators will be incurred.

\section{Ethical considerations}

The principal investigator is updated professional research ethics. He will ensure that the study avoids plagiarisms and violations of refugees and especially vulnerable group rights and conventions and shall, therefore, abide by all the core ethical principles such asbeneficence, justice and exhibit respect for the rights of the vulnerable and refugee rights as stipulated in Geneva conventions of human rights. The study shall be subjected to full ethical review by local ethical review committee for authorization and monitoring. Authority to conduct the study in the settlement camps will be sought from the United Nations High commissioner for Refugees (UNHCR) which shall evaluate direct benefits of this study for the individual refugees and internally displaced persons who will participate in study as well as expected benefits for the host communities in South Sudan in which the study will take place including overall potential benefits to science and the world at large.

\section{Other expected support for the project}

WHO, World Bank, USAID will be sought for funding support?

\section{Collaboration with scientists or other research institutions}

This study will be conducted fully in collaboration with another scientist from various universities in East African mainly Uganda and abroad mainly, Geneva Foundation for medical education and research and Texila American University Public health Department. 
Texila International Journal of Public Health

Volume 4, Issue 4, Dec 2016

\section{Financing, Implementation, and management}

Funds will be wired to Across an international Christian Non-Governmental Organization (INGO) which has operated in South Sudan since the 1970s. Across is currently partnering with UNHCR and manages 2 refugee camps in Central Equatorial State within South Sudan.

\section{Declaration conflict of interest}

The Author works as an expatriate staff for Across, therefore, there is the likelihood of a conflict of interest.

Jennifer Swann_Prof. Lehigh University, Dr. Wanyama_UNFPA, Dr. Petros Gebrewold_UNHCR, Dr. Wamala_WHO, Dr. Allan_WHO, Dr. Brenda Rwanda University of Science, Dr. Albert_IRC, Dr. Abate UNHCR, Sebit Mustafa_UNHCR, Oliot_Cavendish University Uganda. And lastly my course supervisor Suma Menon Faculty Member.

\section{References}

[1]. Kinney M V, Boldosser-Boesch A, McCallon B. Quality, equity, and dignity for women and babies. Lancet. 2016;6736(16):16-17. doi:10.1016/S0140-6736(16)31525-2.

[2]. Denno DM, Hoopes AJ, Chandra-Mouli V. Effective Strategies to Provide Adolescent Sexual and Reproductive Health Services and to Increase Demand and Community Support. J Adolesc Heal. 2015;56(1):S22-S41. doi:10.1016/j.jadohealth.2014.09.012.

[3]. Bill F, Foundation MG. Measuring the health-related Sustainable Development Goals in 188 countries: a baseline analysis from the Global Burden of Disease Study 2015. Lancet. 2016:1813-1850. doi:10.1016/S01406736(16)31467-2.Accessed on 23/09/2016

[4]. United Nations, Conference I. A /69/62. 2014;22369(February):1-286.

[5]. Laski L, Wong S. Addressing diversity in adolescent sexual and reproductive health services. Int J Gynaecol Obstet. 2010;110 Suppl:S10-S12. doi:10.1016/j.ijgo.2010.04.011.

[6]. Who. Quality Assessment Guidebook-A guide to assessing health services for adolescent clients. Circuit World. 2009;5(1):14-14. doi:10.1108/eb043585.

[7]. Nove A, Matthews Z, Neal S, Camacho AV. Maternal mortality in adolescents compared with women of other ages $\square$ : evidence from 144 countries. 1990:155-164. doi:10.1016/S2214-109X(13)70179-7.

[8]. Hindin MJ. "Setting research priorities for adolescent sexual and reproductive" - Google Search. 2015:1-14. http://www.google.com/search?hl=en\&client=safari\&tbo=d\&rls=en\&q=\%22Setting+research+priorities+for+adoles cent+sexual+and+reproductive\%22\&oq=\%22Setting+research+priorities+for+adolescent+sexual + and+reproductive \%22\&gs_l=serp.3...4523.11357.0.11566.3.3.0.0.0.0.52.12.

[9]. Mowjee T. HPG Background Paper. Development. 2004;44(0):0-29.

[10]. Galati AJ. HIGHLIGHTS Guttmacher Policy Review. Guttmacher Policy Rev. 2015;18(4):77-84.

[11]. Horton R. Offline: The future for women's and children's health. Lancet. 2016;387(10032):1982. doi:10.1016/S0140-6736(16)30306-3.

[12]. Lancet T. No peace of mind in South Sudan. Lancet (London, England). 2016;388(10041):212. doi:10.1016/S0140-6736(16)31076-5.

[13]. CHF. Common Humanatarian Fund. S.Ignals. 2005.

[14]. Spiegel P, Golub G. Refugees and health: Lessons from World War 1. Lancet. 2014;384(9955):1644-1646. doi:10.1016/S0140-6736(14)61896-1.

[15]. Office for CHF. Overall Humanitarian Needs in South Sudan. 2014.

[16]. Response Plan. humanitarian Response;South Sudan (December 2016).

[17]. Svanemyr J, Amin A, Robles OJ, Greene ME. Creating an enabling environment for adolescent sexual and reproductive health: A framework and promising approaches. J Adolesc Heal. 2015;56(1):S7-S14. doi:10.1016/j.jadohealth.2014.09.011.

[18]. Victora C, Requejo J, Boerma T, et al. Countdown to 2030 for reproductive, maternal, newborn, child, and adolescent health and nutrition. Lancet Glob Heal. 2016;(16):2015-2016. doi:10.1016/S2214-109X(16)30204-2. 
Texila International Journal of Public Health Volume 4, Issue 4, Dec 2016

[19]. Paul Weis. The 1951 Refugee Convention: The Travaux préparatoires analysed with a Commentary. UN High Comm Refug. 1990:1-272.

[20]. Weis P. The Convention Relating to the Status of Stateless Persons. Int Comp Law Q. 1961;10(2):255-264. doi:10.1093/iclqaj/10.2.255 